\title{
Editorial
}

\section{A national registry for wound research - a new frontier for Australia?}

\section{Sandy-Hodgetts K}

For referencing Sandy-Hodgetts K. A national registry for wound research - a new frontier for Australia? Wound Practice and Research 2021; 29(1):5.

DOI https://doi.org/10.33235/wpr.29.1.5

For some time now, there has been a growing call around the world for the use of national research data registries to unite clinicians, scientists, researchers, bioinformatics specialists, health economists and epidemiologists in order to understand patient outcomes on a large scale, and attempt to answer burning research questions. All of this activity has the primary endpoint of informing health policy, evidence-based practice and improved health outcomes. Pooling and sharing of data provides a great opportunity to measure clinical outcomes, determine the prevalence of a disease state, or understand whether we need to return to the drawing board and reframe a hypothesis.

The question is now are the days of working in silos becoming numbered? A new age of health and medical research has dawned, and one of its key tenants is the development and use of national networks and data registries to scale research activities and boost the implementation of findings. Collaborating with our neighbours is the new black. As an example, I often look to those surgical disciplines such as oncology, respiratory or cardiovascular medicine who have led the way in advancing their fields through the use of the highest research standards and constantly look for new ways of testing their hypotheses, including forming research registries and networks. This has been much to the benefit

\section{Dr Kylie Sandy-Hodgetts}

Chair National Steering Committee Australian

Wound Research Directory - Australian Health

Research Alliance of improved patient outcomes and accelerating advances in their fields.

So, after several decades of wound care research in Australia, why are we still seeing some of the same wound care challenges touted over 20 years ago? In the same breath, there have been some extraordinary research achievements in wound care in our nation; however, they are often restricted to implementation in one state or territory. Why, in this wide brown land, girt by sea, have we not solved some of our major conundrums in Australian wound care? Are we too isolated, even in our own backyards?

One of the first steps is to connect the wound research community across states and territories. A major national initiative led by the Australian Health Research Alliance in partnership with West Australian Health Translation Network and Brisbane Diamantina Partners and Wounds Australia will attempt to address some of these contemporary challenges in wound care today.

One of these is to establish a national registry for wound care research in Australia. This registry will serve as a database of those who are active in wound care research - pure and lab science, translational medicine, clinical trialists, and chronic, acute, primary, community care and allied health research sectors - and will provide the opportunity to communicate and expand networks to solve our greatest challenges today. If you are active in wound care research, share your story, and join us on this journey! Stay tuned for further details. Let's take wound care research in Australia into the 21st century.

\section{$\bar{\tau}_{0}-$ Healthcare products home-delivered}

We offer a comprehensive range in:

- Continence

- Respiratory

- Wound care

- Mobility aids and equipment

- Skin care

- Pressure management and bedding

Supporting

NDIS

participants

since 2013

- Nutrition

Call us or visit our website:

(c) 1300886601

@ orders@brightsky.com.au

(6) www.brightsky.com.au

All proceeds from BrightSky go towards helping people with physical disability and their support network

www.brightsky.com.au

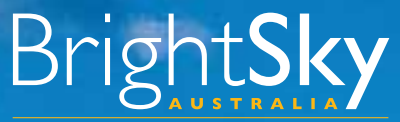

Supporting people in our community 